\title{
WHAT IS INNOVATIVENESS: LITERATURE REVIEW
}

\author{
Wojciech NASIEROWSKI*, Francisco J. ARCELUS** \\ Faculty of Administration, University of New Brunswick \\ Fredericton, N.B. E3B 5A3, Canada \\ *e-mail: nasierow@unb.ca \\ **e-mail: arcelus@unb.ca
}

\begin{abstract}
For decades what has been heated are debates on topics such as: which country is the most competitive? What is the best country to live in?. However, it may be disputable whether results of these debates have practical outcomes. It is arguable whether is it clear what constructs are in fact discussed, how to measure their level, and how to draw conclusions from such studies. This paper addresses aspects relevant to innovativeness - interpretation, measurement, accuracy and practicality. This paper shows that despite of very abundant literature on the subject, the prime tangible effect deals with various rankings of countries for public relations purpose rather than it provides a policy setting directions.
\end{abstract}

Keywords: competitiveness, innovativeness, indicatoring innovativeness, efficiency, measure of efficiency.

1

\section{Introduction}

Aspects of competitiveness and innovativeness are currently probably among the most frequently exercised conversations relating to discussions about economic progress and prosperity. Numerous studies highlight the crucial importance of innovation to economic development and well-being (e.g., McArthur \& Sachs [45], Porter [57], Rutten \& Boekema [60], Blanke et al. [9], TEP [69], Lööf \& Heshmati [42]). It is accepted that one must be innovative in order to be competitive. It should be noted though that innovation can be interpreted in different ways (FM [23], OM [56], Rogers [59]). Various interpretations of innovation make for an imposing obstacle when researching this subject. As a consequence the same is true of the notion innovativeness, along with the recognition of means that enhance its levels. Since innovativeness is considered to be a complex issue, and its measurement is not possible within the framework of accepted definitions of innovativeness, indicators and indexes are used in order to "quantify" this construct (e.g., Dosi et al. [17], Archibugi \& Coco [4], IUS [34], Sajeva et al. [62], Freudenberg [26], Saisana \& Tarantola [61], Katz [37, p. 893], Arundel \& Hollanders[5], Schibany \& Streicher [65]). This renders possible to "measure" levels of innovativeness, and rank countries with respect to their dedication to innovativeness (e.g., IUS [34], Sajeva et al. [62], Hollanders \& Van Cruysen [32], Arundel \& Hollanders [6], Nasierowski [51], [52]). The results of this activity may be indicative of organizational, legal, social, and political means and arrangements conducive to augmentation of innovativeness.
These arrangements can be discussed within the scope of the concept of National Innovation Systems (e.g., Dahlman [15, p. 541], Dosi et al. [17], Freeman [25], Lundvall [44], Nelson [55], Shariff [68], Nasierowski [53]). However, when researching the subject "innovations", each of the steps from invention (innovation) to NIS, is punctuated with lack of precision, somewhat denotes a type of a discussion which started, yet has not produced a conclusion.

This paper intends to review the current stock of experience with interpretation and assessments of innovativeness. First, various perspectives to innovativeness are explored. Then, aspects of indicatoring (measurement) of innovativeness is reviewed, along with examination of the practicability of such attempts. The concluding section provides some suggestions for further studies. As well, it is explained why addressing these questions is warranted from practical and theoretical viewpoints.

\section{Concepts of innovativeness revisited}

One of the problems relevant to research on innovativeness is a difficulty to establish a precise definition for the following constructs: innovation, invention, creativity, and entrepreneurship: definitions that would allow quantification of these constructs. Scholarly discourse on these definitions has created a dizzying array of differing and sometimes contradicting explanations. Some attribute this state of affairs, at least in part to miss-definitions, or misinterpretations of what above mentioned constructs denote (e.g., Rogers [59]; Seng 
Tan $[67, \mathrm{p} .1])$. There seems to be agreement on considering innovation to be a novelty applied to something which already exists. The disagreement arises as to whether the change should be new to the market in general or only to a particular company (e.g., Välimäki, et al. [70]). The former, denoted for the purposes of this discussion as the Frascati [23] approach suggests that innovation is rooted in notion of novelty in global terms. These novelties are assessed indirectly by the level of various educational attainment statistics (EIS [20], KAM [36], R\&D expenditures EIS [20], IUS [34]), and patent counts (e.g., Grilliches [29], Khan \& Dernis [39]). The latter, the Oslo Manual (OM [56]) approach, takes a more micro perspective. It deals primarily with implementation and adaptation of solutions, and is oriented on a practitioner's viewpoint. This approach conceptualizes innovation as an application for commercial purposes.

Inventions often originate as a result of systematically undertaken Research and Development (R\&D) activities. The following is a definition offered by the United Nations, which is also accepted by OECD in the Frascati Manual: "R\&D is a creative work undertaken on a systematic basis in order to increase the stock of knowledge, including knowledge of man, culture and society and the use of this stock of knowledge to devise new applications The basic criterion for distinguishing $R \& D$ from the rest of Science and Technology is that there is an appreciable element of novelty" (FM [23, § 63]). "Technical innovation activities are all of the scientific, technological, organizational, financial and commercial steps, including investments in new knowledge, which actually, are intended to, lead to the implementation of technologically new and improved products and processes (FM [23, p. 18]), and that are crucial to a company's survival (e.g., Jamison and Hård [35]). From the Frascati perspective, innovations are those solutions implemented in technologically new products / processes, or to products/processes, subject to significant technological improvements, that exhibit characteristics of novelty.

When such interpretations of innovation are accepted, then the majority of SMEs do not qualify as being innovative. These types of enterprises mainly imitate and adopt solutions. It is a very sound business concept. Next, inventiveness is only one element in the innovation process. $R \& D$ activities (leading to inventions) are only initial stages of the innovation process, which can be described in many different ways (e.g., Kline \& Rosenberg [40, p. 289], Betz [8, Chapter 1-2], Nasierowski [54]). The concept of novelty in global terms is not emphasized in these models, and hence a weakened interpretation of novelty and innovation can be adopted. Innovations in an enterprise can be defined as an economic decision made in order to carry out tasks related to taking advantage of emerging market opportunities, or to preventing threats from materializing. Such decisions are often of strategic nature. They may have consequences for the competitive position of the company and to all aspects of its functioning; in short, they may bring profits. A similar interpretation is advocated by Oslo Manual [56], where the minimum requirement for something to be termed an "innovation" is for the product or process to be new or substantially improved for the specific company.

Schumpeter [66] defines the economic phenomenon of innovation as a process that takes an invention and develops it all the way to a marketable product or service that changes the economy. It can be conceptual or perceptual, should be related to opportunities, focused, and can be breathtakingly simple (Drucker [18]). Innovation can also be interpreted as a process specific to a period of time or particular region, which means that the introduction of an "old technology" to the region, with no previous exposure to this technology, is also an innovation. For example, Sajeva, et al. [62, p. 7] define innovation as "the process leading to the adoption and diffusion of new technologies, aimed at creating new processes, products and services. While the term adoption represents the final stage of an invention, diffusion focuses on the supply of new goods and services to the customer. In this context, innovation is the method to achieve competitiveness in the framework of the revised Lisbon agenda." Such view is also consistent with the Europe2020 Strategy.

Although such interpretations enhance discussions on innovativeness, the quantification of innovativeness or level of involvement in new activities remains a perplexing, multidimensional, concept. One can advocate an indirect means for the measurement of innovations. For example, levels of productivity, employment, revenues, or the betterment of competitive position can be used to measure innovativeness. Further measures may include the examination of distinctive competencies, or of quality. Such indicators, however, depend on the context of operations, market conditions, actions undertaken by competition, economic and political situations in the region, reputation of the company, 
and customer loyalty. These may all have a strong impact on results of "indicatoring" of innovation. Quantification of these processes is almost impossible in light of diversity of possible contextual factors. We deal with very dynamic systems, and "many of their properties emerge from interactions among the entities in them" (Katz [37, p. 893]). Interrelationships between and among these factors of innovativeness are not documented, and the measurement of innovation processes may fail to provide evidence regarding casual relationships.

Another troubling issue in the study of technological change is differentiating innovation from creativity. Innovation can be defined as an output (product, device, theory, etc.) that is somewhat new to the place, time, or purpose of its application. Innovation occurs as a result of successful implementation of creative ideas within an organization. Creativity, on the other hand, is the development of a novel and useful idea in any domain and is a seed for all innovations (Amabile [3]). Innovation is always creative but not all creativity is innovative. "In this view, creativity by individuals and teams is a starting point for innovation: the first is a necessary but not sufficient condition for the second". In short, creativity is a manifestation of a drive to shape an opportunity, whereas innovation is an attempt to apply this opportunity practically. Creativity is a process, which may not lead to implementation. To that end, identification or development of creative ideas and an ability to implement them are among the most important abilities of successful entrepreneurs.

For many practitioners "innovation refers to the development and improvement of products and processes arising from the exchange of knowledge among firms and other players in their environment" (CEDO [10], p. 2). Such interpretations stem from the concept advocated by the Oslo Manual (OM [56, $\S 131])$, where a minimum requirement of innovation is for a product or a process to be new (or substantially improved) for the specific company: it need not be new in global terms. Thus, innovativeness deals with implementation of new solutions in the place or for the purpose, for which these have not been used earlier. Some public institutions also take a similar micro/practitioner's approach. For example, the Atlantic Canada Opportunities Agency (ACOA) recognizes the fact that innovation means different things to different people. In their terms, innovation is "a process through which economic value is extracted from knowledge through the generation, development, and implementation of ideas to produce new or improved products, processes, and services. Innovation encompasses much more than $R \& D$ or technological change. Innovation makes knowledge useful and turns it into wealth and prosperity" (ACOA [1, p. 8]).

It has been observed, that several items from the composite indexes, that may relate to the notion of innovativeness, deal primarily with inventiveness (e.g., on the Input side - expenditures on R\&D and S\&E graduates, or on the Output side - patents and trademarks). Thus, these indicators fall more towards Frascati interpretation of innovations (hence inventions) (FM [23, $\S 21$ and 63]), quite a difference from innovations as interpreted by Oslo Manual (OM [56, § 131]). Consequently, it is arguable, whether these common composite indexes serve the needs of practitioners oriented towards the interpretation of innovations of enterprises aimed at improvement of economic prosperity at a "shop floor level" (Drucker [18]), or are primarily a manifestation of pro-innovation policies and mechanisms at the macro-economic level.

Further difficulties lie awaiting the researchers when they try to formulate plans for stimulating innovativeness and creativity, as well as entrepreneurship enhancement, along with attempting to improve economic performance of firms. And as if this is not enough, differences regarding interpretations are further amplified when micro and macro-economic perspectives are taken into account. It is observed that two perceptions of innovativeness can be identified; they refer to the same phenomenon, though from varying perspectives. One deals with a macro-economic view, suitable for big inventive companies, and levels of innovativeness are measured by composite indexes. The second perspective is more "shop-floor" oriented and deals with problems of changing ideas into commercial success. The first is leaning towards inventiveness, the second towards commercialization. Micro- and macro- perspectives are somewhat different 'worlds' - explained by state policies and international competitiveness determinants on one side, and a drive to increase competitive position and profits of an enterprise on the other. These two 'worlds' coexist, and more coordination of their principles and related activities may bring positive results. It would be incorrect to attempt to discuss the two as the same phenomena, and there is a need to identify means to bridge the gap between 'macro' and 'micro' perceptions and interpretations of innova- 
tion (Nasierowski [51], [52] and [53]). Hence, a comparison of concepts of innovativeness from the viewpoint of macro-economic indicators (e.g., as expressed by the EIS [20]/ IUS [34]), with opinions/perceptions of entrepreneurs that will provide a micro-economic perspective to the problem (Drucker [18], INNO [33]) is warranted. These considerations are expected to aid in finding better means to assist companies in enhancing their performance, thus contributing to economic progress at the macro-economic level.

The European Commission (IUS [34]) adopts a comprehensive approach to the definition of innovativeness and attempts to combine both macro- and microapproaches. The term innovation not only describes innovation as an invention or technological improvement, but also includes the implementation of new ideas, processes and methods for leveraging existing ideas, technologies or inventions. Discussion is no longer limited to products, processes or technologies (e.g., Kedia \& Bhagat [38]), or spin-offs (Arundel \& Hollanders [6, pp. 4-10]), but also focuses on an overall replication of solutions that have been used somewhere else, or used for a separate purpose. The term innovation not only describes innovation as an invention, or a technological improvement, but also includes in its scope the implementation of new ideas, processes and methods for leveraging existing ideas, technologies or inventions further.

Thus, under the specific constraints, intuitive understanding of the concept "innovativeness" may be necessitated, though it may affect the precision of discussion about this concept. This situation is quite similar to psychological studies, where the vacuum of a sharp definition for intelligence is pragmatically filled by equating intelligence with IQ tests results. The researches of innovativeness face similar dilemmas of imprecision, as psychologists with definitions and interpretations of intelligence. The value of IQ is considered to be an objective measure. However, because intelligence is near impossible to precisely define, controversies surround the IQ tests. There is a debate about what exactly they do measure, and whether or not they indeed measure any objective value. In order to avoid fruitless quests by trying to define the exact meaning of intelligence, some psychologists accept that "intelligence is the phenomenon measured by IQ tests". Consequently, researchers of innovativeness may be forced to accept that innova- tions are what composite indexes of innovativeness indicate.

\section{Indicatoring innovativeness}

Assuming that definitions of invention, innovation, innovativeness are accepted, the next step in the discussion on the subject may deal with identification of indicators/indexes that will assist in measuring levels of innovativeness. Results of such "measurements" will allow a more quantitative discussion on available means for improvement. Some frequently referred to indexes are described below.

- The Growth Competitiveness Index (GCI) as published in the Global Competitiveness Report is based on three "pillars"(McArthur \& Sachs [45]):

- macroeconomic environment - assesses the stability of macroeconomic situations (e.g., through a tight monetary policy, low inflation) (macroeconomic stability, government waste, and country credit rating sub-indexes),

- institutions - assure a favorable climate for longterm economic and business activities (e.g., contracts, law, and corruption sub-indexes), and,

- technology - captures features of technological progress (innovation, ICT, and technology transfer sub-indexes).

These three sub-indexes are then combined to calculate the overall GCI.

- The Knowledge Economy Index (KEI) of the World Bank is prepared based on the Knowledge Assessment Methodology (KAM) (e.g., Chen \& Dahlman [12], KAM [36]), and highlights the importance of knowledge for long-term economic growth. Some 80 data series are grouped into: performance indicators; economic incentives; institutional regime; innovation system; education and human resources; information infrastructure.

This information forms the basis for identifying four sub-indexes, emphasizing the use of:

- existing and new knowledge and the flourishing of entrepreneurship,

- an educated and skilled population to create, share, and use knowledge well,

- a dynamic information infrastructure to facilitate the effective communication, dissemination, and processing of information, 
- an efficient innovation system of firms, research centers, universities, consultants and other organizations to tap into a growing stock of global knowledge, to assimilate and adapt it to local needs, and to create new technology.

- The Human Development Index (HDI) is prepared within the United Nations Development Program, and is a "composite index measuring average achievement in three basic dimensions of human development - a long and healthy life, knowledge and decent standard of living" [30].

- The World Competitiveness Yearbook Index (WCYI) is prepared by IMD. Its objective is to analyze the facts and policies that shape a nations ability to create and maintain an environment of value creation for its enterprises and more prosperity for its people (WCY [72]). Based on 312 criterion, including data from various sources and an annual Executive Opinion Survey, there are four categories:

- economic performance, which measures the macro-economics of the domestic economy,

- government efficiency, which evaluates the extent to which government policies are conducive to competitiveness,

- business efficiency, which assesses the extent to which enterprises are performing in an innovative, profitable, and responsible manner,

- infrastructure which denotes the extent to which basic, technological, scientific and human resources meet the needs of business.

- The European Innovation Scoreboard / Innovation Union Scoreboard (an influential concept in the EU countries) is sponsored by the European Commission. Some 24 (26) indicators are used in order to create the EIS / IUS Index. These indicators are arbitrarily grouped into scales (categories), and classified as:

- inputs (human resources, finance and support, firm investments, throughputs); and,

- outputs (innovators, economic effects).

Each composite index consists of sub-indexes, where all items are equally weighted. This methodology may be challenged for correctness in terms of selecting (and grouping) indicators: numbers should indicate the number and nature of the factors that describe the idea. Moreover, several items are highly correlated - they carry the same information with regard to statis- tical significance of results (and country rankings) thus some information is redundant. This methodology, in principle, is characteristic of all composite indexes presented.

Each studied index captures some information related to economic improvement. Since these items are correlated, it should be asked which ones act as stimuli for the development of other ideas. It can be asked whether many indicators are needed in order to measure innovativeness? and whether a compressed index of innovativeness can be constructed? Furthermore, with quite limited number of observations (countries) and many variables a non-parametric tests of efficiency cannot be done. Thus, a number of variables should be compressed. Certainly, a "compression" produces a tradeoff between notions - index as a policy making drive versus index as a platform for ranking purpose.

Composite indexes use a variety of indicators (data series) to "measure" innovativeness. In such a way, they specify which items of economic performance may contribute to the enhancement of innovativeness. This may provide policy formulation related suggestions for governmental agencies for example. Inherently, however, an assumption is made that some 'policies', as measured by innovativeness indicators, will produce similar results irrespective of specific context in various countries. This may not be a correct assumption.

Freudenberg [26] provides a fairly extensive overview of composite indexes of country performance related to economy, environment, globalization, society, and innovation / technology. These indexes include, for example, the Growth Competitiveness Index (GCR [27]), the Knowledge Economy Index (Chen \& Dahlman [12]), the Human Development Index (HDR [30]) and the World Competitiveness Report Index (WCY [72]). Composite indexes are used in a variety of economic performance and policy areas. Such indexes integrate large amounts of information into easily understood formats and can be manipulated to produce desired outcomes. Despite this, there are several methodological problems regarding the creation of composite indexes (Saisana \& Tarantola [61]). Quandaries occur when examining the accuracy and reliability of these indexes. Problems of missing data are imminent, along with the question of index sensitivity to the weighing of indicators and their aggregation (Freudenberg [26, p. 5]). 
Composite indexes are intended to measure different phenomena: however, they produce similar results in terms of ranking of countries: thus, they may measure the same aspects. The need and/or usefulness of such diversity among indexes is questionable. Despite being created with different intentions, and using varying series' of data for calculations, these composite indexes actually produce similar results when raking countries (Mirchandani [46], Nasierowski [47]). This occurs irrespective of whether they intend to measure level of innovative capability, competitiveness, productivity, level or wealth, or standard of living. There is a chance that a there are more simple means to measure innovativeness.

Albeit these problems exhibited by indexes of innovativeness, there has been a noticeable proliferation of composite indexes (e.g., Archibugi \& Coco [4, pp. 179-181]). It should be noted that the preceding discussion does not negate the usefulness of these indexes. Rather, the results question the need for other indexes that replicate the rankings of alternate or better established measures.

\section{$4 \quad$ About practicalities of indicatoring innovations}

Even though diverse interpretations of creativity, innovativeness and entrepreneurship may enliven possible discourses about their nature imperatives and effectiveness, it does not help find a reasonable way to measure them. For example studies that make the tall claim of measuring innovation (or productivity of innovation generating units) by recording number of patents, publications, etc seem hollow and incomplete because they completely ignore the meaty qualitative dimensions of innovation, while excessively fixating on the quantitative dimensions. This leads one to advocate an indirect means for measuring innovation. We can measure innovation by evaluating factors such as productivity, employment, revenue or profit increase, improvement of competitive position, creating distinctive competencies, or quality (if such indicators can indeed be measured). Yet, these indicators depend upon a variety of factors such as the specific context of operations, market forces, actions undertaken by competition, economic and political influences shaping the particular region, company's reputation, and customers loyalty, all of which may significantly impact results of innovation measurements.
It is quite a task to measure the impact of innovation upon business performances given the insidious presence of market forces. Also quantification of these processes is virtually impossible taking into account diversity and numerous possible contextual factors. It is highly unlikely that companies will disclose information regarding their innovation related procedures, nor would they allow outsiders to observe their processes. Thus, the intimates of the relationship between these factors will not be documented. Moreover, measurement of innovation processes may fail to provide evidence regarding casual relationship, which additionally may be of a non-linear character.

It is at times accepted that composite indexes may serve as a policy setting mechanism (that has been also one of the objectives of the EIS / IUS approach). However, recommended innovation policies should not be considered as "an average" of responses from different sectors, by companies of different size, which operate within very different economic, political, and social context. An assumption that - "indicators have policy implications" - is difficult to endorse. Presented observations suggest that countries should adopt different innovation policies. Consequently, the power of indexes as a tool that sets direction for policy formulation is substantially decreased.

Problems arise when using composite indexes also due to the conceptual quandary between allocative efficiency ('are we doing the right things?') versus technical efficiency ('are we doing things the right way?'). Further dilemmas stem from problematic definitions and the various taxonomies used to measure the consequences of the output achieved (e.g., Seng Tan [67]).

\section{About efficiency of pro-inovative approaches}

Increases in innovation and the benefits that result from such an attitude are important factors in fostering economic activity and boosting competitive advantage. The vital role of innovation in national competitiveness is recognized by most nations. Knowing a nation's strengths and weaknesses allows a government to institute interventions aimed at fostering its innovation record. Therefore attempts to "measure" levels of innovativeness, along with assessment of efficiency / effectiveness of pro-innovative policies, have been undertaken. One may identify two basic approaches to estimate effectiveness: 
- the first, probably the most popular now, where the level of innovativeness is determined as a sum, or a ratio, of inputs and outputs to the innovation processes. In such a case, one may expect, that the higher the input the higher the output, and hence the higher the level of innovativeness. This is the underlying assumption of the EIS / IUS approach, and its associated composite index of innovativeness - probably the leading approach to measure levels of innovativeness in Europe. This concept has been "developed by the European Commission, under the Lisbon Strategy, to evaluate and compare the innovation performance of its Member States" (EIS, [20, p. 3]),

- the second, where the efficiency of organizations (systems, approaches) is denoted with the use the "best practice frontier" concept: here the distance from such a frontier represents inefficiency - in other words the inability to produce maximum output from given inputs. This approach is linked to the effectiveness approach to National Innovation Systems, the line of thinking about the issue initiated by Arcelus and Nasierowski (Balazat \& Hanush [7, pp. 202-203]).

\subsection{Country rankings as a measure of efficiency}

One of the main assumptions of composite indexes (and the EIS / IUS approach in particular), is that indicators that create the innovativeness index, should have practical implications. The level of innovativeness can be impacted by regulations and national innovation policies. This trend may also be rooted in recommendations of Aho Report [2] that suggests "a 4-pronged strategy focusing on the creation of innovation friendly markets, on strengthening R\&D resources, on increasing structural mobility as well as fostering a culture which celebrates innovation". However, data series used in these composite indexes change almost every year. Consequently, there is no possibility of identifying whether policy changes have contributed to the improvement of desired operational outcomes.

The information content of EIS / IUS can be examined from the viewpoint of ranking countries against each other, and compared to other indexes that assess economic prosperity of countries. However, recommended innovation policies should not be considered as "an average" of responses from different sectors, or by companies of different size, which operate within very different economic, political, and social contexts. Thus, the assumption used in the EIS / IUS approach - "that indicators have policy implications" - is difficult to endorse. Results derived from the EIS / IUS reports present only a partial picture of the innovativeness of countries. This data focuses on a country's ranking, and whether they are a leading country, exhibit average performance, are catching up, or are losing ground. As was earlier outlined, it is recommended that emphasis be placed on the simplicity of composite indexes without compromising their explanatory power. Also, it is important that aspects of efficiency are addressed in a way which permits better modeling of EU policies to sectorial and regional specificity. Such ranking does not take specific economic and social conditions of the country into account, and emphasizes quantitative dimension of the issue - "the more the better". However, it is equally important to know whether or not resources available are used efficiently

It is reasonably clear from the preceding discussion that the methodological base given in EIS / IUS is not exempt from controversy. These reports give equal weight to each factor, thereby having the average of the factor loadings as the overall country measure from which to obtain the ranks. The issue of contention when assessing levels of innovativeness is the weight to assign to each factor in computing the overall score for each country. Yet: why each component enters the index with the same weight for all countries, regardless of whether or not the outputs and inputs themselves enter the computation equally weighted? There is the lack of evidence that items are equally important in the rankings. This implies, again, that the process of identifying the inputs and outputs required in the computation of the appropriate index of innovativeness makes the implicit assumption of all countries being equally efficient in the transformation of their inputs into their outputs.

A possible solution to this problem is to weigh each factor by the percentage of the total variance explained by the said factor and /or to compute the measure of efficiency on the basis of the factor loadings obtained through the principal component analysis. Even if this approach is used than still an important question remains unanswered: in practice, it is possible for two different countries to utilize totally different amounts of resources to produce an equivalent amount of outputs, without this difference being reflected in the index of innovativeness. Similarly, it is equally possible 
for two different countries to employ similar sets of resources and yet produce different output amounts.

This leads to the important issue relative to the assessment of the technical efficiency (EFF) of countries in the process of transforming inputs into outputs. From a micro-economic perspective, such issue epitomizes the concept of Paretto-Koopmans efficiency (Varian [71]), related to the ability of a country to minimize the number of inputs required to produce the maximum set of outputs possible. A country "is fully efficient if and only if it is not possible to improve any input or output without worsening some other input or output." (Cooper [14, p. 45]).

\subsection{Measuring technical efficiency}

While accepting the importance of innovative activities for economic well being of nations, it is warranted to examine the efficiency of turning inputs of innovativeness into outputs that enhance social welfare. Several studies on the efficiency of organizations (systems, approaches) use the "best practice frontier" concept. Here the distance from such a frontier represents inefficiency: in other words the inability to produce maximum output from given inputs. Parametric approaches (e.g., regression methods) are used to estimate parameters of technical efficiency. However, many elements, such as multicollinearity, model misinterpretation and measurement error, the use of multiple outputs, and omitted variables, can weaken the precision of these parameter estimates (Chapple et al. [11]). Consequently, it may be more appropriate to depart from a cursory examination of a ratio of inputs to outputs, and examine "best practice frontiers" from the viewpoint of contemporary economic concepts using the non-parametric DEA model in order to estimate the Farrell Input -Saving Measure of Technical Efficiency. This means that the measure of technical efficiency is examined as the greatest proportion of inputs which can be reduced and still produce the same output (Färe \& Grosskopf, [21, p. 14]). Constraints of such an approach include the requirement of a specific ratio of observations (countries considered) to number of variables (indicators) used to describe the situation. In such a case the use of DEA is not possible: a more simplistic composite index is needed in order to evaluate the efficiency of national innovativeness efforts. Several papers have reported results related to the use of this approach (e.g., Nasierowski [47], [48], Nasi- erowski \& Arcelus [49], [50], Hollanders \& Esser [31]).

Two crucial characteristics of a country's production process have an important impact on the efficiency computations. These are returns to scale (RS) and congestion (CON), two key concepts of production economics (e.g., Cooper [14], Coelli et al. [13], Wei $\&$ Yan [73]).

RS deals with the rate of change in the inputs utilized, as compared, with the rate of change in the outputs obtained. Constant RS (CRS) occur, when the rate of changes in the inputs equals that of the output. Alternatively, if rates differ from each other, there is evidence of variable returns to scale (VRS). Another RS index is associated with the non-increasing returns to scale (NRS). The second characteristic, congestion, deals with the cost of disposing of unwanted inputs. The inefficiency arises from the fact that the presence of congestion requires the use of resources for the elimination of the undesirable inputs that would otherwise have gone to generate more outputs. "Evidence of congestion is present when reductions in one or more inputs can be associated with increases in one or more outputs - or, proceeding in reverse, when increases in one or more inputs can be associated with decreases in one or more outputs - without worsening any other input or output." (Cooper [14]). Examples of input congestion appear in Coelli, et al. [13, p. 195], among many others, in cases of government or union-based controls on the use of certain inputs. The literature employs the terms weak (WD) and strong (SD) disposability to denote whether evidence of congestion exists or not.

Some results of application such a procedure have indicated that (Nasierowski [51], [52]):

- To be efficient, the average country should cut down some volume of inputs utilized for the generation of the outputs and still produce the same level of outputs. Part of that inefficiency is due to scale and congestion problems.

- The average country's technological base is operating of the basis of decreasing returns to scale. Therefore, from an examination of those countries operating under a DRS technology, it is clear that their inefficiency is mostly scale related, with almost no congestion. A testable proposition of this state of affairs is that these countries are largely the heaviest investors in innovation over 
time and that, at present, are at the decreasing end of their returns on any new investment.

- CRT countries that operate at CRT appear to have some rather minimal congestion problems; otherwise, they are highly efficient in their allocation of resources.

- IRS countries, arguably at the other side of the investment scale, have a much lower EFF index, due almost equally to Scale and Congestion problems, and they still exhibit some technical inefficiencies, not due to either congestion or scale.

Characteristically almost all countries that are classified as "leaders" of innovation operate under decreasing returns to scale (DRS), which can indicate, that improvements are becoming more and more difficult. "Catching-up" countries operate predominantly under constant return to scale, which may indicate, that no strong attempts for improvement is made there. These observations call for further study, though; it should not come as a surprise that leaders in terms of input-to / output-from innovation are frequently technically not effective. For small countries there may be a permanent problem with achieving optimal Return to Scale because of lack of economies of scale and associated synergies. In other cases, problems with congestion may result from a lack of clearly identified patterns of specialization, poor coordination between government supported research institutions and business, inefficient commercialization of inventions, and inadequate transfer of knowledge between various agents involved in pro-innovative activities. Such conclusions call for a more detailed examination, and in particular, detailed assessment of mechanisms embedded in NIS of countries.

Efficiency of turning inputs into outputs is as important as the level of inputs. The use of a non-parametric DEA model provides a methodological extension to the methods for investigation of innovation systems. Farell Input Saving Measure of Technical Efficiency (EFF) can be used to investigate aspects of efficiency of proinnovation efforts. The results of application of such a methodology may have both practical and scholarly merits. Practical outcomes will directly indicate reasons for inefficiencies, provide suggestions regarding crafting pro-innovative policies, guide operational activities, and simplify assessment of efficiency of activities based on quantitative evidence. Efficient countries and their policies will be identified, thus outlining Best Management Practices (BMP) in the area of stimulation and support of innovativeness. Such results may supplement currently exercised concepts. Scholarly benefits of the study results deal with the contribution to an ongoing debate about the means in which to stimulate innovation, to determine the ranking of countries, and to establish the theoretical underpinnings of being an innovation leader. This methodology may bring novel perspectives to the investigation of the problems of innovativeness.

\section{$6 \quad$ Instead of summary}

In the myriad of reports on interpretations of innovativeness it is somewhat counterproductive to argue which interpretation is more correct or appropriate. While continuing to studying the topic, a clear interpretation should be accepted and consistently used. Under the circumstances it is acknowledged that innovativeness is a multidimensional, complex phenomenon; not defined precisely; not prone for operationalization, and its interpretation may be impacted by several situational elements and interdependencies between subdimensions. Certainly, it would be very convenient to get access to a comprehensive composite index of innovativeness that is simple and clear; based on easily available and reliable data; an index that remains unchanged in terms of indicators selected over prolonged period of time; that captures issues of inventiveness and innovativeness; pertinent for big as well as for small enterprises; that may contain policy-setting suggestions.

The assessment of technical efficiency of innovation efforts is probably the most desirable outcome of further studies. Based on the assessment of efficiency the key points for policies oriented on enhancing innovativeness can be established. These key points, along with the results of analysis of detailed innovation policies, may lead to the identification of "Best Management Practices in Innovations" (BMPI), that applicable to the specific context. If some stability while measuring innovativeness is achieved, longitudinal studies may be undertaken cross-validating assessment of accuracy of procedures and policies. Results will bring more clarity to the quandary: are countries and companies innovative because they are rich, or is it vice-versa, and countries and companies become rich when they become innovative. Certainly the problem of isolation of results of assessments from market forces and contextual elements should be explained. When results of such studies become available a more precise 
taxonomy of countries can be developed. As it stands now, "the more you spend the better is country's ranking": such a classification can be enhanced with comments regarding efficiency in terms of utilization of available resources. Again, conclusion from such a study may assist in identification of the extent to which the alleged decrease in the productivity growth of many countries can be explained by differences in efficiency and by differences in its components, namely scale and congestion. Some results, along this line of reasoning have been already published (Nasierowski \& Arcelus [49]). These results indicated, that globalization of business practices lead to the harmonization of policies dealing with the acquisition and development of technology throughout the years and across countries. Additionally, a classification of countries into two clusters based on their commitment to technology development has been presented. Indexes of commitment to technological change were identified and countries were ranked according to their technological competitiveness. These results may also be influential in terms of operationalization of National Innovation Systems and the clarification of the dichotomy between macro-economic perceptions of innovativeness and micro-economic reality.

There are still several important to economic progress topics in the field of innovativeness which exploration is warranted. Some prepositions to be investigated:

H1: Rich countries are not technically efficient in the area of innovativeness because of congestion.

$\mathrm{H} 2$ : Small countries are not technically efficient in the area of innovativeness because of insufficient economies of scale and deficiencies in synergies in undertaken projects.

H3: Problems of congestion and scale are exacerbated when there are structural problems with formulation of NIS (e.g., inadequate specialization patterns, insufficient coordination mechanisms, deficiencies in management of NIS, etc.).

H4: Rich countries frequently overinvest. Frequently, countries classified as non-innovative, indeed invest less in innovations, but do it efficiently.

\section{REFERENCES}

[1] ACOA - Fast Forward: An Innovation Guide for Small and Medium Enterprises. ACOA, Fredericton.
[2] Aho Report - Creating an Innovative Europe: Report of the Independent Expert Group on $R \& D$ and Innovation Appointed Following the Hampton Court Summit, 2006, http://europa.eu.int/inwest-inresearch.

[3] Amabile T.M. - Entrepreneurial Creativity Through Motivational Synergy [in] Journal of Creative Behavior, 31(1), 1997, pp. 18-26.

[4] Archibugi D., Coco A. - Measuring Technological Capabilities at the Country Level: a Survey and a Menu for Choices [in] Research Policy, 34, 2005, pp. 175-194.

[5] Arundel A., Hollanders H. - Policy Indicators And Targets: Measuring the Impact of Innovation Policies. European Commission, 2005.

[6] Arundel A., Hollanders H. - 2006 Trend Chart Methodology Report: Searching the Forest for the Trees: "Missing" Indicators of Innovation. MERIT - Maastricht Economic Research Institute on Innovation and Technology, 2006.

[7] Balzat M., Hanusch H. - Recent Trends in the Research on National Innovation Systems [in] Journal of Evolutionary Economics, 14, 2004, pp.197-210.

[8] Betz F. - Managing Technology: Competing through New Ventures, Innovation, and Corporate Research. Prentice-Hall, Englewood Cliffs, 1987.

[9] Blanke J., Fiona P. Sala-i-Martin X. - The Growth Competitiveness Index: Analyzing Key Underpinnings of Economic Growth. Global Competitiveness Report of the World Economic Forum, 2003 (Chap.1.1.).

[10] CEDO - Emerging Regional Practices in Support of SME Innovation. Montreal, Canada Economic Development Observatory, 2001.

[11] Chapple W., Lockett A., Siegel D., Wright M. Assessing the Relative Performance of U.K. University Technology Transfer Offices: Parametric and Non-Parametric Evidence [in] Research Policy, Vol. 34 (3), 2005, pp. 369-384.

[12] Chen D.H.C., Dahlman C.J. - The Knowledge Economy, the KAM Methodology and World Bank Operations. The World Bank, Washington DC 20433, 2005.

[13] Coelli T.J., Rao D.S.P., O'Donnell C.J., Battese G.E. - An Introduction to Efficiency and Productivity Analysis. Springer, New York 2005.

[14] Cooper W.W., Seiford L.M., Tone K. - Data Envelopment Analysis and its Uses. Springer, New York 2006.

[15] Dahlman C.J. - Technology Strategy in East Asian Developing Countries [in] Journal of Asian Economics, 5, 1994, pp. 541-572. 
[16] Dernis H., Khan M. - Triadic Patent Families Methodology. STI Working Paper 2004/2, OECD, Paris 2004.

[17] Dosi G., Freeman C., Nelson R., Silverberg G., Soete L. - Technological Change and Economic theory. Pinter Publishers, London 1988.

[18] Drucker P. - Innovation and Entrepreneurship: Practice and Principles. Harper \& Row, New York 1985.

[19] Edquist C. - Systems of Innovation: Technologies, Institutions, and Organizations. Pinter, London 1997.

[20] EIS - European Innovation Scoreboard 2005: Comparative Analysis of Innovation Performance, European Trend Chart on Innovation, 2005.

[21] Färe R., Grosskopf S. - Reference Guide to OnFront ${ }^{\circledR}$. Economic Measurement and Quality I Lund AB, Lund 1998.

[22] Färe R., Grosskopf S. - User's Guide to OnFront ${ }^{\circledR}$. Economic Measurement and Quality I Lund AB, Lund 1998

[23] FM - Frascati Manual: The Measurement of Scientific and Technological Activities. OECD, Paris 2002.

[24] Freeman C. - Technology and Economic Performance: Lessons from Japan. Pinter, London 1987.

[25] Freeman C. - The National System of Innovation in Historical Perspective [in] Cambridge Journal of Economics, Vol. 19, 1995, pp. 5-24.

[26] Freudenberg M. - Composite Indicators of Country Performance: A Critical Assessment [in] STI Working paper 2003/16, Industry Issues, OECD JT00153477, 2003.

[27] GCR - The Growth Competitiveness Report. 20042005, 2005, Global Competitiveness Report of the World Economic Forum.

[28] GII - Global Innovation Index 2009, www.management today.co.uk/news/610009/ (accessed on 2009.03.16).

[29] Griliches Z. - Patent Statistics as an Economic Indicator: A Survey [in] Journal of Economics Literature, 28 (4), 1990.

[30] HDR - Human Development Report: International Comparison at a Crossroads: Aid, Trade And Security in an Unequal World. Published for the United Nations Development Programme, New York 2005.

[31] Hollanders H., Esser F.C. - Measuring Innovation Efficiency. ProInno Europe - InnoMetrics, 2007.

[32] Hollanders H., van Cruysen A. - Rethinking the European Innovation Scoreboard: A New
Methodology for 2008-2010. ProInno Europe, Inno-Metrics, Maastricht 2008.

[33] INNO - What is Innovation?, 2006, http://www.hi.is/ joner/eaps/innodd.htm (accessed on 11.04.2007).

[34] IUS - Innovation Union Scoreboard 2010, InnoMetrics, 2011.

[35] Jamison A., Hård M. - The Story-Lines of Technological Change: Innovation, Construction and Appropriation [in] Technology Analysis and Strategic Management, 15, 200381-91.

[36] KAM - The Knowledge Assessment Methodology and Scorecards 2006,

http://vle.worldbank.org/gdln/Programs/kam2001 /methodology.htm (accessed on 24.08.2006).

[37] Katz S. - Indicators for Complex Innovation Systems [in] Research Policy, 35 (7), 2006, pp. 893909.

[38] Kedia B., Bhagat R.S. - Cultural Constraints on Transfer of Technology across Nations: Implications for Research in International and Comparative Management [in] Academy of Management, 13, 1988, pp. 559-571.

[39] Khan M., Dernis H. - Global Overview in Innovative Activities from the Patent Indicators Perspective. STI Working Paper 2006/3, OECD, Paris 2006.

[40] Kline S.J., Rosenberg N. - An overview of Innovation. National Academy Press, Washington DC. 1986.

[41] Lisbon Strategy - Strategia Lizbońska: droga do sukcesu zjednoczonej Europy, Wyzwania członkowstwa. Urząd Komitetu Integracji Europejskiej, Ideapress, Gdansk 2002.

[42] Lööf H., Heshmati A. - On the Relationship Between Innovation and Economic Performance [in] Economics of Innovation and Technological Change, 15, 2006, pp. 317-344.

[43] Lundvall B.A. - National Innovation Systems - Analytical Concept and Development Tool [in] Industry and Innovation 14 (1), 2007, pp. 95-119.

[44] Lundvall B.A. (ed) - National Systems of Innovation: Towards a Theory of Innovation and Interactive Learning. Pinter Publishers, London 1992.

[45] McArthur J.W., Sachs J.D. - The Growth Competitiveness Index: Measuring Technological Advancement and the Stages of Development, in the Global Competitiveness Report 2001-2002. New York: Oxford University Press for the World Economic Forum 2003. 
[46] Mirchandani D. - Economic and Social Indicators of Global Competitiveness: an Analysis of Country Rankings. 8th International Eastern Academy of Management Conference, (CD Rom version), Prague 1999.

[47] Nasierowski W. - Some Observations Regarding Composite Indexes of Economic Performance. North-East Decision Sciences Institute Conference, New York 2008.

[48] Nasierowski W. - Zarzqdzanie rozwojem techniki: Perspektywa krajowych systemów. Seria EuroManagement, Poltext, Warszawa 1997.

[49] Nasierowski W., Arcelus F. - On the Efficiency of National Innovation Systems [in] Socio Economic Planning Sciences, Vol. 37, 2003, pp. 215-234.

[50] Nasierowski W., Arcelus F. - Interrelationships Among the Elements of National Innovation Systems: A Statistical Evaluation [in] European Journal of Operations Research , Vol.119, 1999, pp.235-253.

[51] Nasierowski W. - About Technical Efficiency of Efforts to Enhance Innovativeness in European Union [in] International Journal of Innovation and Technology Management, Vol. 7, Issue 4, 2010, pp. 389-404.

[52] Nasierowski W. - Composite Indexes and Indicators of Innovativeness: Some Critical Comments [in] Global Management Journal, Vol. 2, No 1, 2010, pp. 40-49.

[53] Nasierowski W. - A Conceptual Framework for Formalization of National Innovation Systems [in] Foundations of Management, Warsaw University of Technology, Vol. 1, No. 2, 2009, pp. 159-166.

[54] Nasierowski W. - Zarzqdzanie rozwojem techniki: Perspektywa krajowych systemów. Seria EuroManagement, PolText, 1998 Warszawa.

[55] Nelson R. (ed.) - National Innovation Systems. A Comparative Analysis. Oxford University Press, New York/Oxford 1993.

[56] OM, Oslo Manual - OECD Proposed Guidelines for Collecting and Interpreting Technological Innovation Data. OECD/EuroStat, Paris (KBN 1999).

[57] Porter M. - Competitive Advantage of Nations. Free Press, New York 1990.

[58] Rodriguez-Pose A. - Is R\&D Investment in Lagging Areas of Europe Worthwhile? Theory and Empirical Evidence. Regional Science, 2001, pp. 275-295.

[59] Rogers M. - The Definition and Measurement of Innovation. Melbourne Institute of Applied Economic and Social Research, The University of Melbourne, 1998.
[60] Rutten R., Boekema F. - Innovation, Policy and Economic Growth: Theory and Cases [in] European Planning Studies, Vol. 13, issue 8, 2005, pp. 1131-1136.

[61] Saisana M., Tarantola S. - State-of-the-Art Report on Current Methodologies and Practices for Composite Indicator Development. Joint Research Centre - European Commission, I-21020 Ispra (VA), Italy 2002.

[62] Sajeva M., Gatelli D., Tarantola S., Hollanders H. Methodology Report on the European Innovation Scoreboard 2005. European Commission, Enterprise Directorate-General, 2005.

[63] Sarasvathy S.D. - Causation and Effectuation: Toward a Theoretical Shift from Economic Inevitability to Entrepreneurial Contingency [in] Academy of Management Review, 26(2), 20012, pp. 43-288.

[64] Schwartzman S., de Souza A. - Evaluation And Efficiency Of Research And Experimental Development (R\&D) Institutions And Units,

http://www.schwartzman.org.br/simon/rd inst.htm

[65] Schibany A., Streicher G. - How not to Compare Innovation Performance: A Critical Assessment of the European Innovation Scoreboard. Joanneum Research Institute of Technology and Regional Policy, Vienna 2008.

[66] Schumpeter J.A. - Economic Theory and Entrepreneurial History [in] Change and the Entrepreneur: Postulates and Patterns for Entrepreneurial History (ed. A.H. Cole). Cambridge, MA, Harvard University Press, 1949, pp. 63-84.

[67] Seng Tan B. - The Consequences of Innovation [in] The Innovation Journal: The Public Sector Innovation Journal, 9 (3), 2004, pp. 1-42.

[68] Shariff N. - Emergence and development of the National Innovation System concept [in] Research Policy, Vol. 35, 2006, pp.745-766.

[69] TEP - Technology and the Economy: The Key Relationships. The Technology/ Economy Programme, OECD, Paris1992.

[70] Välimäki H., Niskanen A., Tervonen K., Laurula I. - Indicators of Innovativeness and Enterprise Competitiveness in the Woods Products Industry in Finland [in] Scandinavian Journal of Forestry Research, 19 (Supplement 5), 2004, pp. 90-96.

[71] Varian H. - Intermediate Microeconomics: A Modern Approach. New York: Norton 2002.

[72] WCY, World Competitiveness Yearbook. IMD, Lausanne, Switzerland 2011.

[73] Wei Q., Yan H. - Congestion and Returns to Scale in Data Envelopment Analysis [in] European Journal of Operational Research, 153, 2004, pp. 641660. 